\title{
An Empirical Study on the Employability Structure of Pharmacy Graduates
}

\author{
Yan Huang ${ }^{1}$, Qin Fang ${ }^{2}$, Kunling Weng ${ }^{3} \&$ Boyang $\mathrm{Yu}^{1}$ \\ ${ }^{1}$ School of International Pharmaceutical Business, China Pharmaceutical University, Nanjing, China \\ ${ }^{2}$ Co-first Author, School of Science, China Pharmaceutical University, Nanjing, China \\ ${ }^{3}$ School of Science, China Pharmaceutical University, Nanjing, China \\ Correspondence: Boyang Yu, School of International Pharmaceutical Business, China Pharmaceutical University, \\ Nanjing 211198, China. E-mail: boyangyucpu@163.com
}

Received: April 14, 2017

doi:10.5539/jsd.v10n3p204
Accepted: May 2, 2017 Online Published: May 31, 2017

URL: https://doi.org/10.5539/jsd.v10n3p204

\begin{abstract}
In this paper, through the interviews and questionnaires of the experts of medical colleges and universities in China, the executives of pharmaceutical enterprises and the graduates of pharmaceutical specialty, we use statistical analysis techniques such as exploratory factor analysis and confirmatory factor analysis to present and verify the pharmaceutical structural model of the employment ability of undergraduates. The results show that the structure of employment ability of the undergraduates of pharmaceutical specialty in China can be divided into four dimensions: Development ability, Social ability, Professional ability and Personal quality, and there is some correlation between these four dimensions. Among them, the innovation ability has the greatest impact on the development of pharmaceutical undergraduates. The organization and coordination ability has the greatest impact on social capacity of pharmaceutical undergraduates. The operational ability has the greatest impact on professional competence of pharmaceutical undergraduates; and the professional ethics has the greatest impact on personal quality of pharmaceutical undergraduates.
\end{abstract}

Keywords: graduates of pharmacy, employability, factor analysis, structural model

\section{Introduction}

In recent years, the number of undergraduates in colleges and universities is increasing year by year. In 2015, the number of ordinary college graduates was 7.49 million, an increase of 220,000 over 2014, which had increased $3 \%$. However, the number of undergraduates in 2003 was only 212 million, we can conclude that the average growth rate reached 11.09\% from 2003 to 2015. According to The Employment Report of Chinese College Students in 2016 (Note 1), the employment rate was $91.7 \%$ of 2015 graduates after six months statistics, of which the employment rate for undergraduates was $92.2 \%$, and the vocational college graduates made up $91.2 \%$. Gradually increasing the number of graduates and the not fully employment rate yearly made a considerable number of college graduates facing a huge employment pressure after their graduation. Meanwhile, with the reform of China's pharmaceutical industry supply side, "small-scale, low-capacity" pharmaceutical companies are gradually being eliminated, and it also made the employment enrollment rate decreased year by year, which lead to the pharmaceutical employment market gradually saturated, and the pharmaceutical graduates faced fierce competition and challenges in employment.

According to the requirements of the National Medium and Long Term Education Reform and Development Plan (2010-2020) (Note 2), The main task by recently is to comprehensively improve the quality of higher education and the quality of personnel training. The improvement of the quality of higher education is to improve the quality of college students by the end, which is the key to countries competition. As a part of the overall quality of college students, take a study on the employment ability of college students can better improve the quality of students and it also can help graduates get the right employment development jobs.

In order to provide a useful reference for pharmacy graduates in training and improvement of the employment ability, this paper empirically analyzes the structure of employment ability by constructing the structure model of employment ability and analyzes the dimensions of the employability structure and the impact of individual competencies on various dimensions. 


\section{Investigation and Data}

\subsection{Questionnaire Development}

In this paper, the questionnaire development of employability for pharmacy undergraduate students is mainly including Literature collation, Individual interviews and Expert discussion these three steps.

The first step is Literature collation. According to the existing literature results on the concept and structure of undergraduate graduates employment ability, we sorted out and listed 58 specific measurement items, and then classified and summarized them accordingly.

The second step is Individual interviews. After the semi-structured interviews for medical college experts and pharmaceutical companies executives, we deleted 21 unsuitable items and reserved 37 items.

The last step is Expert discussion. We invited human resources professional teachers, college students career guidance center teachers, and the teachers who at least have one of the graduates to assess the rationality and readability of these items, which we got from the front two steps. Also, in this process we summarized and deleted some items according to their suggestions. At last, we got a questionnaire of employability for pharmacy undergraduate students with 22 items.

By the project analysis and exploratory factor analysis method, we analyzed this questionnaire and refined the results. At last, we got an initial test scale of employability for pharmacy undergraduate students.

Unifying the initial test scale with the basic personal information, accomplishments and the employment status, which can be picked up from pharmacy undergraduate students, we create a new questionnaire of employability for pharmacy undergraduate students. And, a confirmatory factor analysis of the employment ability model with states from the initial questionnaire of pharmacy undergraduate students.

\subsection{Sample Distribution}

Through the questionnaire survey system to generate online version of the initial questionnaire, we separated investigated the practitioners by cluster sampling method in the five state enterprises Pharmaceutical with the initial questionnaires. The details of those five state enterprises Pharmaceutical are: Guangzhou Pharmaceutical Group Baiyunshan Pharmaceutical Factory, Lianyungang Hengrui Pharmaceutical, Hausen Pharmaceutical, Merck (China) Company and Sinopharm Holdings state company (Beijing branch). In this questionnaire, we have issued 530 copies and received 497 copies, at last, we got 456 valid questionnaires, and this valid rate is $91.75 \%$.

At the same time, we take a second questionnaire to the samples as same as the initial questionnaire and just changed the cluster sampling method to random cluster sampling method. In this questionnaire, we issued 800 copies and received 742 copies, at last, we got 683 valid questionnaires, which makes up $92.05 \%$ of the total copies.

\subsection{Dates Analysis}

We analyzed scale dates of employment ability for pharmacy undergraduate students from the initial questionnaires by using project analysis method, exploratory factor analysis method and reliability test method with SPSS 19 software (Yu \& He, 2003). Also, we used AMOS 21 software to exploratory factorial analyzed the scale dates of employment ability for pharmacy undergraduate students from the second questionnaires (Hou, Wen, \& Cheng, 2004).

\section{The Construction and Analysis of the Employment Ability Structure Model of Pharmacy Undergraduate Students}

3.1 Project Analysis

According to the test results of the initial test, this study arranged the sum of the scores from high to low of all participants from the initial questionnaires, and the high top $20 \%$ was set to the high scored group, the $20 \%$ after was set to the low scored group, and then we take a significant test for the score differences of each participant in every items between these two groups from the questionnaires.

If the critical ratio (CR) of the item reaches a significant level ( $\mathrm{P}<0.05$ or $\mathrm{P}<0.01)$, it means that the item can identify the degree of response of the different subjects; if not, the item would be deleted. The results are listed in Table 1. 
Table 1 . The project analysis scale of employment ability of pharmacy undergraduate students

\begin{tabular}{lllll}
\hline Projects & High Scored group & Low Scored Group & $\boldsymbol{P}$ & Significant \\
\hline Innovation ability & 4.93 & 4.12 & 0.000 & Significant \\
professional skill & 4.94 & 3.91 & 0.012 & Significant \\
Problem solving ability & 5.00 & 4.50 & 0.000 & Significant \\
Skills of analyze & 4.99 & 4.24 & 0.000 & Significant \\
Information management ability & 4.97 & 4.35 & 0.056 & non significant \\
Operation ability & 4.95 & 3.89 & 0.038 & Significant \\
Professional knowledge & 4.95 & 3.95 & 0.002 & Significant \\
Practical ability & 4.94 & 3.55 & 0.042 & Significant \\
Learning ability & 4.99 & 4.28 & 0.000 & Significant \\
team work & 4.99 & 4.26 & 0.000 & Significant \\
communication skills & 5.00 & 4.21 & 0.000 & Significant \\
Emotional management ability & 4.99 & 4.36 & 0.062 & non significant \\
Organization and coordination capacity & 4.99 & 3.82 & 0.047 & Significant \\
expression ability & 4.99 & 4.02 & 0.000 & Significant \\
adaptability & 4.99 & 3.98 & 0.004 & Significant \\
Professional ethics & 4.99 & 4.26 & 0.013 & Significant \\
Honesty & 5.00 & 4.39 & 0.022 & Significant \\
Dedication & 4.99 & 4.45 & 0.122 & non significant \\
Pragmatic & 4.99 & 4.08 & 0.054 & non significant \\
Interdisciplinary competence & 4.86 & 4.38 & 0.164 & non significant \\
Excellence & 4.97 & 4.21 & 0.152 & non significant \\
Responsibility & 4.99 & 4.06 & 0.031 & Significant \\
\hline & & & \\
\end{tabular}

From the Table 1, we can see that in the t-test of every items from the scale for the high and low scored group, the Information management ability, Emotional management ability, Dedication, Pragmatic, Interdisciplinary competence and Excellence items are non-significant with $p>0.05$, so they would be deleted, and other 16 items are reached the level of $p<0.05$, So these items should be reserved.

Therefore, through the project analysis, the formal scale of employment ability of pharmacy undergraduate students is composed by these 16 items.

\subsection{Exploratory Factor Analysis}

Before taking exploratory factor analysis, we tested the sample date by KMO test and Bartlett test to check whether the dates are suitable for factor analysis. In the processing of this test, if the KMO value is larger, the more common between variables, which means that these variables are suitable for factor analysis. According to the study of Kaiser (1974), if the KMO value no more than 0.5 , it would be unsuitable for factor analysis (Kaiser, 1974). Following table 2 is the KMO and Bartlett results of Initial scale.

Table 2. KMO and Bartlett's test

\begin{tabular}{lll}
\hline Kaiser-Meyer-Olkin Measure of Sampling Adequacy. & .845 \\
\hline Bartlett's Test of Sphericity & Approx. Chi-Square & 6039.453 \\
& df & 120 \\
& Sig. & .000 \\
\hline
\end{tabular}

We can conclude from Table 2 that the KMO value is 0.845 and the Bartlett test is significant for the initial scale, 
which also indicates this sample data is suitable to take factor analysis.

In the process of the Exploratory Factor Analysis, the following criterion factors have a decisive role in the factor and item quantity:

- The factor eigenvalue is greater than one;

- The entry load for this factor is greater than 0.3 ;

- The factor contains no less than 3 items.

In this study, the maximum variance method was used to carry out the factor analysis, and the gravel diagram was obtained as shown in Figure 1.

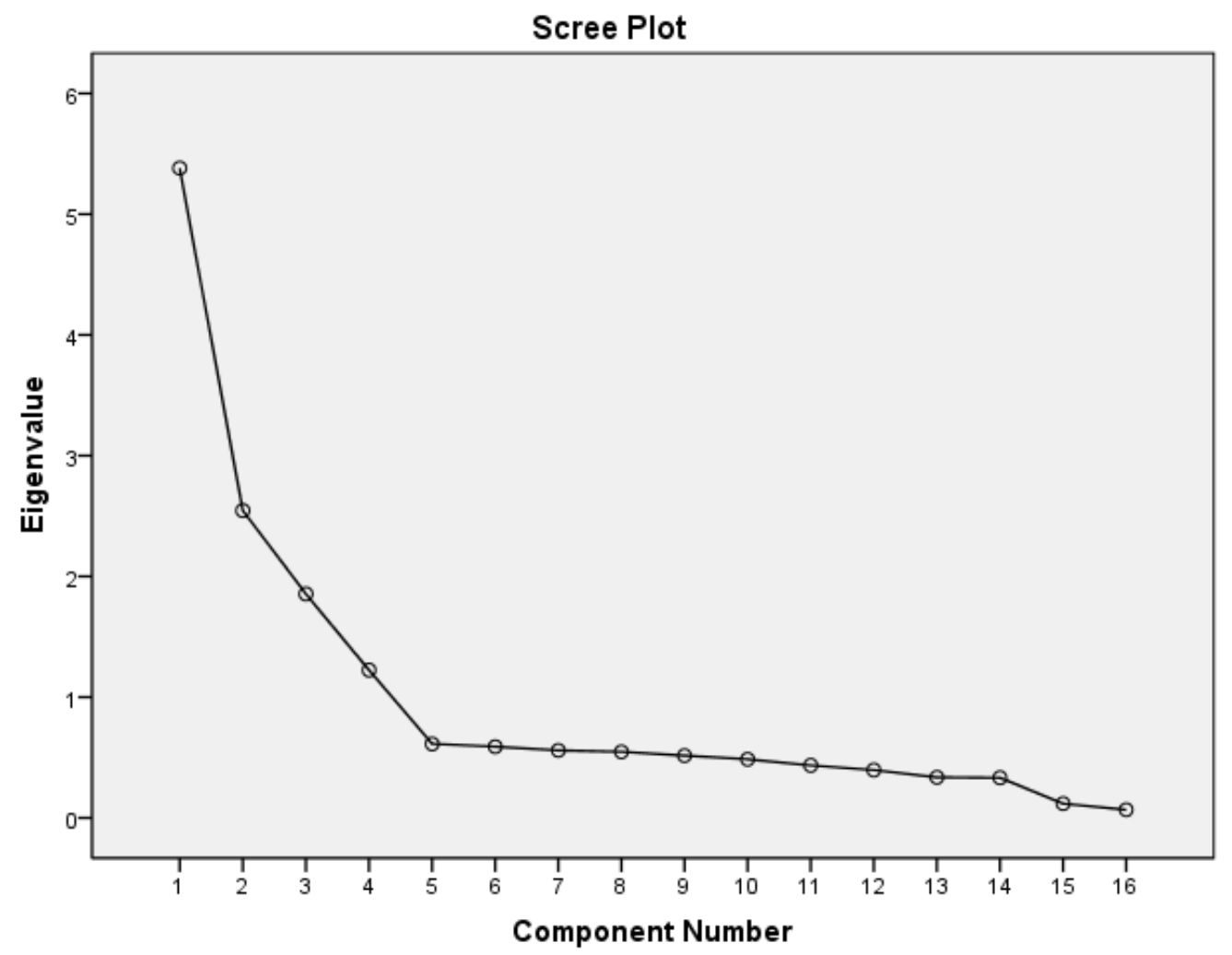

Figure 1. Factor analysis of the gravel map

It can be observed in Figure 1 that there are four factors with eigenvalues greater than 1, so the four factors are extracted and the load values of all the items are all greater than 0.3. All the factors are not less than three, and the explanatory rate of the four factors' cumulative variance is $68.784 \%$. The rotation factor matrix is presented in table 3. 
Table 3. Rotated component matrix ${ }^{\mathrm{a}}$

\begin{tabular}{lllll}
\hline & \multicolumn{3}{l}{ Component } & \\
& 1 & 2 & 3 & 4 \\
\hline 1. professional skill & .069 & .004 & .782 & .086 \\
2. Problem-solving ability & .758 & .185 & .048 & .106 \\
3. innovation ability & .922 & .179 & .066 & .103 \\
4. analyze Skills & .804 & .148 & .027 & .091 \\
5.operational skill & .083 & .130 & .927 & .150 \\
6. Professional knowledge & .053 & .122 & .922 & .121 \\
7. Practical ability & .843 & .111 & .099 & .059 \\
8. Learning ability & .732 & .070 & .101 & .017 \\
9. team work & .199 & .753 & -.005 & .087 \\
10. communication skills & .111 & .767 & .103 & .164 \\
11. Organization and coordination capacity & .180 & .743 & .112 & .198 \\
12. expression ability & .092 & .733 & .062 & .159 \\
13. adaptability & .739 & .070 & -.029 & .124 \\
14. Professional ethics & .176 & .187 & .142 & .815 \\
15. Honesty and trustworthiness & .091 & .149 & .106 & .843 \\
16. sense of Responsibility & .080 & .226 & .111 & .711 \\
Extraction Method: Principal Component Analysis. & & & & \\
Rotation Method: Varimax with Kaiser Normalization. & & & & \\
\hline Rotation convergen
\end{tabular}

a. Rotation converged in 5 iterations.

From Table 3, factor 1 includes six items, namely: problem-solving ability, innovation ability, analytical ability, practical ability, learning ability, adaptability. We name these six items as "development ability". Factor 2 includes four items, namely: teamwork ability, communication ability, organization and coordination ability, expressive ability. We name these four items as "social ability". Factor 3 includes three topics, namely: professional skills, professional knowledge, operational ability. We name these three items as "professional ability". Factor 4 includes three items, namely: professional ethics, honesty and trustworthiness, sense of responsibility. We name these three items as "personal quality".

In summary, the employment structure of graduates of pharmacy graduates is showed in Table 4. 
Table 4 . The structure of employment ability of pharmacy graduates

\begin{tabular}{|c|c|c|}
\hline \multirow{16}{*}{ employment ability of pharmacy graduates } & \multirow{6}{*}{ Development ability } & problem-solving ability \\
\hline & & innovation ability \\
\hline & & analytical ability \\
\hline & & practical ability \\
\hline & & learning ability \\
\hline & & adaptability \\
\hline & \multirow{4}{*}{ Social ability } & teamwork ability \\
\hline & & communication ability \\
\hline & & organization and coordination ability \\
\hline & & expressive ability \\
\hline & \multirow{3}{*}{ professional ability } & professional skills \\
\hline & & operational ability \\
\hline & & professional knowledge \\
\hline & \multirow{3}{*}{ personal quality } & professional ethics \\
\hline & & honesty and trustworthiness \\
\hline & & sense of responsibility \\
\hline
\end{tabular}

\subsection{Reliability, Validity Test}

\subsubsection{Reliability Test}

In this study, SPSS 19 was used to test the reliability of the questionnaires. The results are shown in Table 5.

Table 5. Reliability statistics

\begin{tabular}{lll}
\hline Cronbach's Alpha & Cronbach's Alpha Based on Standardized Items & N of Items \\
\hline .852 & .863 & 16 \\
\hline
\end{tabular}

As can be seen from Table 5, the scale of Cronbach $\alpha$ is 0.852 . According to the study of De Weiliis, if the $\alpha$ coefficient is between 0.60 and 0.70 , it can be acceptable at least, if the acoefficient is between 0.70 and 0.80 , the test is quite good, and if the acoefficient is between 0.80 and 0.90 , the test is very good. Therefore, this scale has a very good reliability.

\subsubsection{Validity Test}

Through the exploratory factor analysis results, it can be seen that the factor structure of the questionnaire for employment ability of the pharmaceutical graduates is clear and conforms to the theoretical conception. The load of the items included in the factor is higher and the degree of interpretation for the overall variance is also high.

\subsection{Confirmatory Factor Analysis}

We used the AMOS21 software to verify the factor analysis of the second questionnaires and set the Development ability, social ability, professional ability, personal quality as A, B, C, D; set the solve-problems ability, innovation ability, analytical ability, practical ability, learning ability, adaptability as A1, A2, A3, A4, A5, A6; set teamwork ability, communication ability, organization and coordination ability, expression ability as B1, B2, B3, B4; set professional skills, practical ability, professional knowledge as C1, C2, C3; set professional ethics, honesty and trustworthiness, sense of responsibility as D1, D2, D3. Following figure 2 is the structure model of employment ability of pharmaceutical graduates. 


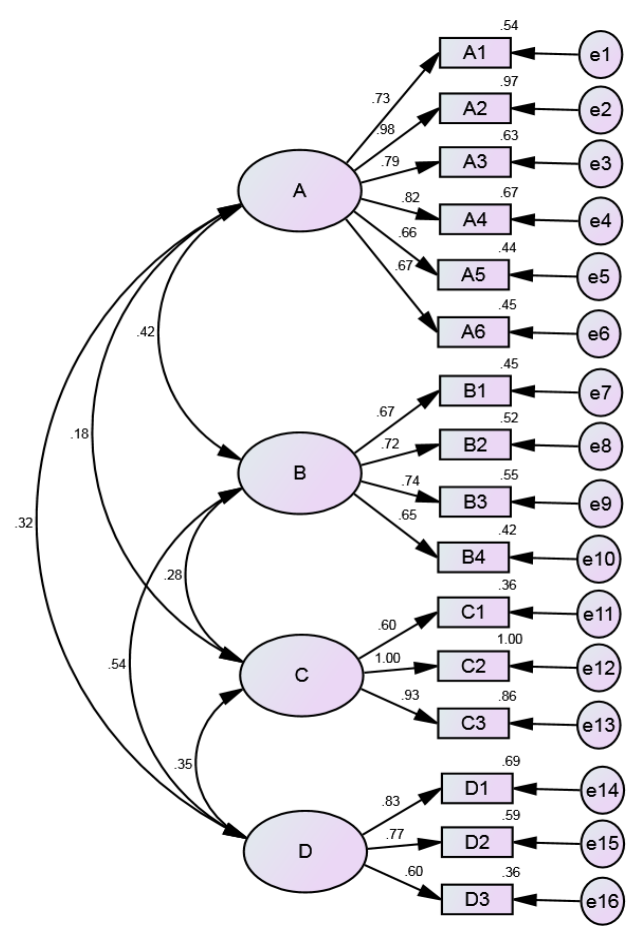

Figure 2. Standardized parameter estimates of the structure model of employment ability for pharmaceutical graduates

It can be observed in Figure 2 that the normalized factor load of the four latent variables on the 16 observation variables is more than 0.6 and there are 10 items not less than 0.72 . In the case of normalization, the complex correlation coefficient between the observed variable and the latent variable is the square of the factor load. Therefore, there are 10 complex correlations coefficients greater than 0.5 , that is to say, the corresponding latent variable can explain more than $60 \%$ of the observed variables. So the model has a strong ability to be believed.

In order to make the evaluation results in reasonable, science and comprehensive evaluation, the model was evaluated by CMIN / DF, CFI, TLI and RMR. CMIN is the difference between the macro function (the difference that the chi-square value). DF is the degree of freedom. If the CMIN/DF is lower than 3 , it means the model fit is better. CFI (Comparative Fit Index), TLI (Tucker-Lewis index), respectively the fitness index, Tucker-Lewis indicators, both values are from 0 to 1 , and the closer to 1 , the better for the model fit. RMR (Root mean square residual) is the root mean square of error, the closer to 0 , the better of the model fit, it is usually using RMR $<0.05$. The fitting degree index of the confirmatory factor analysis is presented in table 6 .

Table 6. Fit index of confirmatory factor analysis

\begin{tabular}{lllllll}
\hline Model & CMIN & DF & CMIN/DF & CFI & TLI & RMR \\
\hline Default model & 139.988 & 98 & 1.428 & 0.993 & 0.991 & 0.008 \\
\hline
\end{tabular}

From the table $6, \mathrm{CMIN} / \mathrm{DF}=1.428$, less than $3 ; \mathrm{CFI}=0.993, \mathrm{TLI}=0.991$, both similar to $1 ; \mathrm{RMR}=0.008$, less than 0.05 , we can see that the effect of various fit index is very good.

\subsection{The Analysis on the Structure of Employment Ability of Pharmacy Graduates}

According to the confirmatory factor analysis, we can see that the structure model and the data fitting degree are high for the employment ability of the pharmacy graduates, the further analysis is followed as:

\subsubsection{Correlation Analysis between Dimensions}

From the structural equation model, the Structure of employment Ability of pharmacy graduates is composed by Development ability (A), social competence (B), professional ability (C), personal quality (D). The associations 
between the four dimensions' variance are shown in Table 7.

Table 7. Covariances: (Group number 1-Default model)

\begin{tabular}{llllllll}
\hline & & & Estimate & S.E. & C.R. & P & Label \\
\hline $\mathrm{A}$ & $<-->$ & $\mathrm{B}$ & .044 & .006 & 7.995 & $* * *$ & par_13 \\
$\mathrm{A}$ & $<-->$ & $\mathrm{C}$ & .022 & .005 & 4.419 & $* * *$ & par_14 \\
$\mathrm{A}$ & $<-->$ & $\mathrm{D}$ & .039 & .006 & 6.827 & $* * *$ & par_15 \\
$\mathrm{B}$ & $<-->$ & $\mathrm{C}$ & .037 & .006 & 5.717 & $* * *$ & par_16 \\
$\mathrm{C}$ & $<-->$ & $\mathrm{D}$ & .055 & .008 & 7.135 & $* * *$ & par_17 \\
$\mathrm{B}$ & $<->$ & $\mathrm{D}$ & .073 & .008 & 9.145 & $* * *$ & par_18 \\
\hline
\end{tabular}

Note. ${ }^{*} \mathrm{p}<0.05,{ }^{* *} \mathrm{p}<0.01,{ }^{* * *} \mathrm{p}<0.01$.

It can be seen from Table 7 that the covariance between the four dimensions is between 0.02 and 0.07 and $p$ $<0.001$ indicates that the correlation between the four dimensions is statistically significant. The correlation coefficient is shown in Table 8.

Table 8. Correlations: (Group number 1 - Default model)

\begin{tabular}{llll}
\hline & & & Estimate \\
\hline $\mathrm{A}$ & $<-->$ & $\mathrm{B}$ & .418 \\
$\mathrm{~A}$ & $<-->$ & $\mathrm{C}$ & .182 \\
$\mathrm{~A}$ & $<-->$ & $\mathrm{D}$ & .321 \\
$\mathrm{~B}$ & $<->$ & $\mathrm{C}$ & .277 \\
$\mathrm{C}$ & $<-->$ & $\mathrm{D}$ & .352 \\
$\mathrm{~B}$ & $<->$ & $\mathrm{D}$ & .538 \\
\hline
\end{tabular}

It can be seen from Table 8 that the correlation coefficient between the four dimensions is between 0.15 and 0.55 , and the correlation coefficient between social competence (B) and personal quality (D) is the highest, reaching 0.538 , which is consistent with the actual situation. In reality, professional ethics, honesty and trustworthiness, sense of responsibility and other personal qualities of the better students, their teamwork, interpersonal communication, organization and coordination, expression and other communicative ability are often better than others, and vice versa. Personal quality and communication skills are complementary, mutual promotion and the "integrity go the world" reflects the truth on some extent. In addition, the medicine is related to the health, and it is closely connected with life, also, the medicine highlights the particularity of pharmacy professional. Thus, the personal quality of pharmacy graduates is to become an important criterion for reference in the process of social intercourse.

The correlation coefficient between development ability (A) and social competence (B) is 0.418 , and there is also a high correlation. This shows that the stronger ability of the students in problem-solving ability, innovation ability, analytical ability, practical ability, learning ability, adaptability, their teamwork, interpersonal communication, organization and coordination, expression and other communication skills are also very high, and vice versa. Each one cannot get better development just rely on himself in the society, so they need to integrate into the collective, communicate with others, learn from each other to self-promotion and strengthen interpersonal relationships and organizations coordination capacity. So the development of capacity and social skills affects each other, more relevant.

\subsubsection{Analysis of the Degree of Impact within Each Dimension}

Each dimension contains a number of measures, each indicator of the corresponding dimension of the non-standardized regression coefficient as show in Table 9. 
Table 9. Regression weights: (group number 1 - default model)

\begin{tabular}{|c|c|c|c|c|c|c|c|}
\hline & & & Estimate & S.E. & C.R. & $\mathrm{P}$ & Label \\
\hline $\mathrm{A} 1$ & $<---$ & A & 1.000 & & & & \\
\hline A2 & $<---$ & A & 1.239 & .047 & 26.376 & $* * *$ & par_1 \\
\hline A3 & $<---$ & A & 1.040 & .049 & 21.266 & $* * *$ & par_2 \\
\hline A4 & $<---$ & A & 1.173 & .053 & 22.121 & $* * *$ & par_3 \\
\hline A5 & $<---$ & A & 1.037 & .059 & 17.520 & $* * *$ & par_4 \\
\hline A6 & $<---$ & A & 1.034 & .058 & 17.757 & $* * *$ & par_5 \\
\hline B1 & $<---$ & $\mathrm{B}$ & 1.000 & & & & \\
\hline B2 & $<---$ & $\mathrm{B}$ & 1.172 & .078 & 14.938 & $* * *$ & par_6 \\
\hline B3 & $<---$ & $\mathrm{B}$ & 1.333 & .088 & 15.237 & $* * *$ & par_7 \\
\hline B4 & $<---$ & $\mathrm{B}$ & 1.133 & .082 & 13.780 & $* * *$ & par_8 \\
\hline $\mathrm{C} 1$ & $<---$ & $\mathrm{C}$ & 1.000 & & & & \\
\hline $\mathrm{C} 2$ & $<---$ & $\mathrm{C}$ & 1.689 & .092 & 18.411 & $* * *$ & par_9 \\
\hline $\mathrm{C} 3$ & $<---$ & $\mathrm{C}$ & 1.619 & .086 & 18.715 & $* * *$ & par_10 \\
\hline D1 & $<---$ & $\mathrm{D}$ & 1.000 & & & & \\
\hline D2 & $<---$ & $\mathrm{D}$ & .838 & .048 & 17.475 & $* * *$ & par_11 \\
\hline D3 & $<---$ & $\mathrm{D}$ & .752 & .052 & 14.558 & $* * *$ & par_12 \\
\hline
\end{tabular}

Note. $* \mathrm{p}<0.05, * * \mathrm{p}<0.01, * * * \mathrm{P}<0.001$.

As can be seen from Table $9, \mathrm{P}<0.001$, it indicating that the impact of each index on the corresponding dimension is statistically significant. The normalized regression coefficients are shown in Table 10

Table 10. Standardized regression weights: (group number 1 - default model)

\begin{tabular}{llll}
\hline & & & Estimate \\
\hline A1 & $<---$ & A & .732 \\
A2 & $<---$ & A & .985 \\
A3 & $<--$ & A & .791 \\
A4 & $<---$ & A & .820 \\
A5 & $<---$ & A & .660 \\
A6 & $<---$ & A & .668 \\
B1 & $<---$ & B & .667 \\
B2 & $<---$ & B & .720 \\
B3 & $<---$ & B & .744 \\
B4 & $<---$ & B & .645 \\
C1 & $<---$ & C & .599 \\
C2 & $<---$ & C & .999 \\
C3 & $<--$ & C & .929 \\
D1 & $<---$ & D & .832 \\
D2 & $<---$ & D & .771 \\
D3 & $<---$ & D & .604 \\
\hline
\end{tabular}

It can be seen from Table 10 that the normalized regression coefficients of each index for the corresponding dimension are between 0.6 and 1.0, where: 
For the development capacity (A), the innovation capacity (A2) has the greatest impact, and the regression coefficient is as high as 0.985 , which is closely related to advocate innovation and encouraging the social status of innovation. Since the 18th CPC National Congress, General Secretary Xi Jinping put forward a series of important thoughts and conclusions on the innovation and development, who raised the innovation and development to the height of the fate of the country and the nation, and placed it at the core of the national development, So the innovation ability have the most influential on personal develop for students. The practical ability (A4) is the second high and the regression coefficient is 0.820 , which is also an important quality for modern teaching and hire to employers. The most important thing for students is to put their theory knowledge and apply themself into practice, which would be better to improve themselves.

For social competence (B), organizational coherence (B3) has the greatest impact, with a regression coefficient of up to 0.744 . Organizational coordination capabilities cover the ability to allocate, control, motivate, and coordinate group activities, and play a key role in achieving organizational goals. So it has a greatest impact on social skills.

For the professional ability (C), the operational ability (C2) has the greatest degree of impact, and the regression coefficient is up to 0.999 . Cultivating students' operational ability, can effectively transfer the students' image thinking to abstract logical thinking, so that students' innovative consciousness and innovation potential can be effectively developed, and the pharmacy profession and the experiment are inseparable, so the ones who have a strong operational ability would have a better understanding of professional knowledge professional skills, so it would have an impact effect on the development of professional capacity.

For the individual quality (D), the professional ethics (D1) has the greatest impact, and the regression coefficient is up to 0.832 . Due to the particularity of the pharmacy profession, the employing units hope that the pharmacy staff has a higher professional ethics. This is the most basic and the most important thing. It is the basic condition for the staff to take the work seriously and to be responsible for the life and health. Candidates who work for the Pharmacy profession have a high degree of professional ethics will naturally be more favored by the employer. Therefore, professional ethics is important in personal quality.

\section{Discussion}

Based on the literature review, the individual interview and the expert discussion, this paper has compiled the questionnaire on the employment ability of pharmacy graduates. By using the project analysis, exploratory factor analysis, confirmatory factor analysis and reliability and validity test, we established the employment ability structure model. The results show that the structure of the employment ability of the pharmacy undergraduates in China can be divided into four dimensions: development ability, social ability, professional ability and personal quality, and there are some correlations between these four dimensions. Among them, Innovation ability has the greatest effect on the development ability; Organization and coordination ability has the greatest effect on social ability; Operational ability has the greatest effect on professional competence, and professional ethics has the greatest effect on personal quality.

For pharmaceutical colleges and universities, they can take this employment ability structure model for reference and targeted teaching, which would be better in fitting the employment needs of employers. For pharmaceutical undergraduate students, they can learn from this employment ability structure model to make a suitable planning for their own study and career, which would be to better improve their employment ability.

\section{References}

Hou, J. T., Wen, Z. L., \& Cheng, Z. J. (2004). Structural Equation Model and Its Application. Beijing: Education Science Press.

Johnson, R. A., \& Wichern. D. W. (2007). Applied Multivariate Statistical Analysis (6th ed.). New York: Published by Pearson Education.

Kaiser, H. F. (1974). An index of factorial simplicity. Psychometrical, 39(1), 31-36. https://doi.org/10.1007/BF02291575

Yu, J. Y., \& He, X. H. (2003). Statistical Analysis of Data and Application of SPASS.

Zhao, D. (2009). The Initial Compilation of Self - Rating Scale for College Students' Employment Ability. Sichuan Normal University. 


\section{Notes}

Note 1. Retrieved from http://www.eol.cn/html/c/2015gxbys/index.shtml

Note 2. http://www.moe.gov.cn/srcsite/A01/s7048/201007/t20100729_171904.html

\section{Copyrights}

Copyright for this article is retained by the author(s), with first publication rights granted to the journal.

This is an open-access article distributed under the terms and conditions of the Creative Commons Attribution license (http://creativecommons.org/licenses/by/4.0/). 